\title{
A LDB e suas alterações Reflexões sobre as normativas em Santa Catarina
}

\author{
Simone Barboza de Carvalho* \\ Gisela Eggert Steindel ${ }^{* *}$
}

RESUMO: Este artigo propõe-se a refletir sobre as alterações sofridas pela Lei de Diretrizes e Bases da Educação Nacional (LDBEN) - especificamente sobre a Lei Federal 10.639/2003, que institui a obrigatoriedade do ensino de História e Cultura Afro-Brasileira em escolas de educação básica públicas e privadas de todo o território nacional. Uma vez que a Lei muitas vezes é desconsiderada como pertencente à própria LDBN, busca-se apreender como a Secretaria de Estado da Educação de Santa Catarina, através de suas Propostas Curriculares de 1998 e 2014, adequou-se a essa alteração.

Palavras-chave: Lei de Diretrizes e Bases da Educação Nacional. Lei Federal 10.639/2003. Proposta Curricular em Santa Catarina.

\section{The LDB (Law on the Guidelines and Bases in Education) and its amendments Reflections on regulations in Santa Catarina}

\begin{abstract}
This article proposes to reflect on the changes undergone by the Law on Guidelines and Bases of National Education (LDBEN) - specifically with Federal Law no. 10.639 / 2003, which establishes the obligation to teach Afro-Brazilian History and Culture in public schools and private institutions throughout the country. Since the Law is often not considered as being part of the LDBN it-
\end{abstract}

* É mestre em Educação pelo Programa de Pós-Graduação em Educação da Universidade do Estado de Santa Catarina e pesquisadora associada do Núcleo de Estudos Afro-Brasileiros - NEAB, vinculado à FAED/UDESC. Lecionou no ensino público municipal e estadual. Florianópolis, SC-Brasil. E-mail: <sicarvalho84@gmail.com>.

* Professora da Universidade do Estado de Santa Catarina. Doutora em Educação pela Universidade de São Paulo e mestre em Ciências da Informação pela Universidade Federal de Minas Gerais. Florianópolis, SCBrasil. E-mail: <f9giza@gmail.com>. 
self, it seeks to understand how the State Secretariat for Education in Santa Catarina, adapted to this change with its Curricular Proposals of 1998 and 2014.

Keywords: Basic laws and directives for national education. Federal law no. 10.639/2003. Proposed curriculum for Santa Catarina.

\section{La LDB y sus cambios}

Reflexiones sobre las normativas en Santa Catarina

RESUMEN: Este artículo propone una reflexión sobre los cambios ocurridos en la Ley de Directrices y Bases de la Educación Nacional (LDBEN), específicamente sobre la Ley Federal 10.639/2003, que instituye la obligatoriedad de la enseñanza de Historia y Cultura Afrobrasileña en las escuelas de educación básica públicas y privadas de todo el territorio nacional. Dado que muchas veces se desconsidera la Ley como parte de la propia LDBEN, se pretende entender cómo la Secretaría de Estado de Educación de Santa Catarina se adaptó a ese cambio por medio de las Propuestas Curriculares de 1998 y 2014.

Palabras clave: Ley de Directrices y Bases de la Educación Nacional. Ley Federal 10.639/2003. Propuesta Curricular en Santa Catarina.

\section{LA LDB* et ses changements Réflexions sur la réglementation dans l'État de Santa Catarina}

RÉSUMÉ: Cet article se propose de réfléchir sur les changements apportés à la Loi de Lignes Directrices et de Bases de l'Éducation Nationale (LDBEN) - spécifiquement sur la Loi Fédérale 10.639/2003, qui établit l'obligation d'enseigner l'Histoire et la Culture Afro-Brésilienne dans les écoles publiques et privées d'éducation basique et ce, sur tout le territoire national. Étant donné que l'appartenance de cette Loi à la propre LDBN est fréquemment ignorée, nous chercherons à comprendre comment le Secrétariat d'État à l'Éducation de Santa Catarina, s'est adapté à ce changement à travers ses Propositions de Programmes Scolaires de 1998 et 2014. 


\section{Mots-clés: Loi de Lignes Directrices et de Bases de l'Éducation Natio- nale. Loi Fédérale 10.639/2003. Proposition de Programme Scolaire à Santa Catarina. \\ * Loi de Lignes Directrices et de Bases}

\section{Introdução}

Lei Federal 10.639/2003 configurou um marco legal importantíssimo dentro
dos estudos da área de Educação das Relações Étnico-Raciais (ERER). Era uma
pauta das reivindicações do Movimento Negro dos últimos trinta anos, pelo menos. Assim, verificar a Lei de Diretrizes e Bases da Educação Nacional (LDBEN) sendo alterada com um texto sucinto, porém tão significativo, foi um ganho. Após mais de dez anos de alteração, perguntamo-nos qual foi o seu alcance e abrangência e se sua implementação segue em curso. Buscamos neste artigo estabelecer pontos de congruência a partir dos documentos legais da Secretaria de Estado da Educação de Santa Catarina.

A Constituição da República Federativa do Brasil, promulgada em 1988 pelo então presidente da, Câmara, deputado Ulysses Guimarães, mostra a inclusão de pequenas pautas relacionadas ao combate ao racismo e a liberdade de expressão quanto à identidade étnico-cultural, além da valorização de todos os sujeitos componentes da sociedade brasileira. No inciso IV do Art. $3^{\underline{0}}$ da Constituição Federal, lemos que é preocupação do Estado "promover o bem de todos, sem preconceito de origem, raça, sexo, cor, idade e quaisquer outras formas de discriminação" (BRASIL, 1988). Esta é uma agenda que há muito o Movimento Negro Brasileiro peleava para incluir nos parâmetros da legislação. Não intentamos nos aprofundar em todo o heroico histórico de atuação do Movimento. No entanto, é primordial o levantamento de algumas conquistas resultantes de suas reivindicações, tais como:

[...] o reconhecimento da Convenção no 111 da Organização Internacional do Trabalho (1958); do Pacto Internacional sobre Direitos Civis e Políticos (1966); do Pacto Internacional sobre Direitos Econômicos, Sociais e Culturais (1966); da Convenção Internacional Sobre a Eliminação de Todas as Formas de Discriminação Racial (1968) [...] e a publicação da Lei nํำ 7.716/1989, a Lei Caó, que define os crimes resultantes de discriminação por raça ou cor (BRASIL, 2006, p.18).

O artigo $242^{\circ}$ da Constituição prevê desde o presente documento a menção a um ensino de História que abranja a visão de todos os sujeitos na construção da identidade nacional, mencionando que "o ensino de História do Brasil levará em conta as contribuições das diferentes culturas e etnias para a formação do povo brasileiro". ${ }^{1}$

No ano de 1996, com a promulgação da Lei de Diretrizes e Bases da Educação Nacional (LDBEN), temos a reafirmação do que já estava prescrito na Constituição Federal, 
indicando novamente a necessidade de as escolas incluírem no ensino de História do Brasil "as contribuições das diferentes culturas e etnias para a formação do povo brasileiro, especialmente das matrizes indígena, africana e europeia". O texto manteve-se praticamente idêntico ao que se apresentava na menção anterior, da Constituição, acrescido somente de quais etnias são legitimadas na formação da nação. No referido trecho consta, de forma redundante, a alusão à importância da matriz europeia no estudo de História. Uma vez que é somente essa vertente que aparece majoritariamente nos materiais difundidos nas escolas até o momento de sua promulgação, parecia-nos desnecessário tal texto. Porém, a menção aos povos africanos e indígenas foi uma retificação importantíssima para as organizações antirracistas e para futura delineação do que viria a tornar-se a mais expressiva política de ação afirmativa educacional.

Assim, no dia nove de janeiro de 2003, é promulgada a Lei Federal de no 10.639, que institui a obrigatoriedade do ensino de Cultura e História Afro-Brasileira e Africana nas escolas de educação básica públicas e particulares de todo o País. A partir daí, legitimar a contribuição das populações de origem africana não é mais uma opção ou recomendação. Por ser um texto muito sucinto e direto, posteriormente, o Governo Federal, através do Conselho Nacional de Educação (CNE), elabora documentos que visavam direcionar de maneira mais pontual o que se esperava das escolas nesse sentido, como as Diretrizes Curriculares Nacionais para o Ensino de Cultura e História Africana e Afro-Brasileira, em junho de 2004, sob a redação de Petronilha Beatriz Gonçalves e Silva. Conforme indicado no texto do parecer, um dos objetivos de sua elaboração é a necessidade de documentos que "orientem a formulação de projetos empenhados na valorização da história e cultura dos afro-brasileiros e dos africanos, assim como comprometidos com a de educação de relações étnico-raciais positivas, a que tais conteúdos devem conduzir" (BRASIL, 2004, p.02). Ademais, o intuito é nortear os possíveis caminhos que contemplarão o previsto na Lei.

\section{Breve relato da educação antirracista catarinense}

\footnotetext{
"Em Santa Catarina, os negros são morenos, embora a função que eles ocupam seja um determinante da cor: quanto menos uma função for considerada própria para o negro, mais branco ele se parece, ou melhor, menos negro ele é. Referir-se a um negro como negro é, na maioria das vezes, constrangedor (para quem está sendo chamado) e ofensivo (para quem chama). Na escola, uma criança ser chamada de negra provoca choro convulsivo. Quando eu me assumi como negra, houve silêncio total na sala. Daí, uma aluna da $3^{\underline{a}}$ série disse o seguinte: 'é uma negra de alma branca, não é, tia?"'. Jeruse Romão - Experiências Educacionais em Santa Catarina (1987) (ROMÃO, 2013, p.140)
} 
O trecho foi extraído de um artigo em que a autora Jeruse Romão relata algumas experiências educacionais ocorridas em 1987, durante a realização de uma pesquisa de extensão. Ilustra muito bem como eram tratados o pertencimento racial e a situação do negro no ambiente escolar na não tão longínqua década de 1980. A política de branqueamento imperava nos discursos e nos modos de ser de negros e não negros. A temática étnico-racial, numa perspectiva como a almejada pelo Movimento Negro catarinense, era suprimida pelo pertencimento europeu apregoado pelo currículo, políticas educacionais e ação docente.

No histórico de ações educacionais antirracistas no cenário catarinense, destacamos como ponto de partida a criação do Núcleo de Estudos Negros (NEN), em que Romão foi coordenadora pedagógica do Programa de Educação entre 1986 e 1994, e de onde provém a experiência do excerto. Fizeram parte do núcleo muitos pesquisadores de referência na temática, como Paulino de Jesus Francisco Cardoso, Ivan da Costa Lima, Sonia Maria Silveira, a já citada Jeruse Romão, entre outros. Certamente, há muitas experiências importantes de que não trataremos nesse artigo. Não obstante, há pesquisas ${ }^{2}$ que procuraram explorar experiências educacionais de afrodescendentes catarinenses em períodos anteriores ao mencionado aqui, e que poderão elucidar como ações educativas direcionadas à essas populações desdobraram-se anteriormente ao evento mencionado (BARROS, 2015, p. 105).

O Núcleo de Estudos Negros (NEN) foi uma entidade fundada por jovens intelectuais e ativistas negros de Santa Catarina e com o propósito de aprofundarem temas educacionais e de identidade afro-brasileira em espaços não-acadêmicos. A data de início das atividades remete ao ano de 1986, e entre suas pautas está a formação de professores, adequação dos currículos visando à inclusão da temática africana e afro-brasileira, produção de material didático-pedagógico, assessoria a entidades na mobilização contra o racismo (LIMA, 1999). Romão descreve as variadas atividades realizadas pelo NEN, numa empreitada para coibir atos de racismo, refletir sobre a questão do pertencimento e, ao mesmo tempo, oferecer estudo e formação para os professores de educação básica. Cita que

Em três seminários contamos com a participação de Togo Ioruba e num dos seminários com a participação de Helio de Assis, também do Rio de Janeiro, que falou sobre o Negro e a Literatura. Foram analisados temas como Negro e Educação; Negro na Literatura e nos Quadrinhos; Negro e Ideologia. Prosseguimos com uma série de seminários onde aprofundávamos os temas debatidos e finalizamos com uma sessão destinada a discorrer sobre propostas de como desenvolver este conteúdo na escola (LIMA, 1999, p.139).

Além dos seminários de formação de professores, salientamos a elaboração e distribuição da série de obras Pensamento Negro e Educação, com títulos como Os Negros, os Conteúdos Escolares e a Diversidade Cultural I e II, e Educação Popular Afro-Brasileira. Nessas 
produções, financiadas pela Fundação Ford há artigos que nos remetem novamente à trajetória e importância do Teatro Experimental do Negro (TEN), experiências escolares envolvendo negros que foram exitosas, à identidade e pertencimento, discriminação, Educação das Relações Étnico-Raciais (ERER) na educação infantil, entre outros. Durante bons anos, era o material existente para apoiar as iniciativas de educadores que já enxergavam a inclusão da temática como primordial nas aulas. As obras datam de 1998 e 1999, ou seja, pós-LDBEN e foram amplamente distribuídas pelas escolas básicas do estado. ${ }^{3}$

Nas propostas educacionais do Estado, e como estas vêm adequando-se às mudanças reivindicadas pelo Movimento Negro Catarinense, e de acordo com as orientações legais, temos como objeto inicial a Proposta Curricular lançada em 1998. É digno de nota recordar que sua elaboração data de um momento também posterior a LDBEN, em que já havia indicativos para a inclusão da temática africana e afro-brasileira pelo menos no estudo da História do Brasil, à parte toda a agenda de uma educação que posicione-se contra o racismo e preconceito, e que ocorra de maneira inclusiva. O documento divide-se em três níveis de ensino, que configuram a grande maioria da educação do estado. Propõe-se a

[...]socialização do conhecimento científico através do acesso amplo e irrestrito a este saber, por todos, considerando, além dos aspectos arrolados neste texto, a formação social brasileira que se caracteriza por sua multiculturalidade étnica e diversidade cultural e a respectiva desigualdade social (SANTA CATARINA, 1998, p.17).

Ressalta-se, no entanto, que os pormenores relacionados à "multiculturalidade étnica e diversidade cultural" podem ser examinados de maneira minuciosa no tópico referente à Educação Indígena, demonstrando do que se trata a multiculturalidade apontada. O documento também traz como princípio a abordagem da diversidade. Porém, não especifica em nenhum momento que diversidade é essa. Pontua que refere-se a uma diferenciação entre os sujeitos, ora relacionada a aspectos cognitivos, ora a aspectos sociais, conforme o trecho a seguir

\footnotetext{
Considerando que o papel da escola é promover a apropriação, elaboração e reelaboração de conhecimento, torna-se necessário que se favoreçam determinados tipos de interações sociais, o que nos remete à discussão acerca do papel do professor na sala de aula e à concepção que fundamenta sua pratica pedagógica (...) através de um currículo que seleciona e valoriza certos componentes, produzem-se limitações e mutilações para todos, mas principalmente para os alunos que se encontram em situação de desvantagem, seja em função de uma deficiência orgânica, seja em função da desigualdade em relação ao capital cultural de origem familiar e social que este alunos carregam (SANTA CATARINA, 1998, p. 74).
}

Frisamos aqui uma ideia muito perturbadora da Proposta, isto é, a de que a diversidade prognostica uma defasagem no "capital cultural". Ademais, é contra essa construção de inferioridade que os movimentos sociais de luta pela valorização dos negros e contra 
o racismo vêm combatendo, para desmistifica-la; e a Proposta Curricular, oriunda de 1998, e já com as orientações previstas na LDBEN, não teve sensibilidade para se adequar. Corroborando com essa falsa concepção hierarquizadora de vivências e conhecimento, exemplifica quais os aportes a serem oferecidos ao aluno em situação de defasagem, como, por exemplo, o Serviço de Apoio Pedagógico, que através de outras dinâmicas, possibilitará a esse aluno, dito diverso, alcançar o nível considerado igualitário aos colegas. Este serviço, conforme o documento,

é uma aposta em uma escola que assuma todos os seus alunos e alunas como pessoas que merecem respeito, descartando modelos seletivos e aprofundando a compreensão que se pode/deve oferecer aos alunos as mesmas possibilidades e experiências educativas, independentemente de sua posição social, econômica, raça, sexo, capacidade intelectual ou qualquer outra característica. É uma aposta em uma escola que, incluindo as diferenças, exclui as desigualdades (SANTA CATARINA, 1998, p. 79).

Posto que a iniciativa se apresenta promissora, é preciso destacar a contradição presente também no fato de que a escola, ao invés de ater-se às particularidades dos alunos, suas vivências, experiências, trajetórias, valorizando-as, busca ferramentas para homogeneizar algo que ela mesma classifica como heterogêneo.

Juntamente com a promulgação da Lei Federal 10.639/2003, Santa Catarina assiste a criação de um importante núcleo de estudos dentro da Secretaria de Educação - o Núcleo de Estudos Afrodescendentes (NEAD). Foi oficialmente instituído

em 19/11/2003, através da Portaria 038/SED (...) é composto por representantes das Gerências de Ensino da Diretoria de Educação Básica e Profissional - DIEB/SED, tendo como colaboradores as gerências regionais de ensino, Conselho Estadual das Populações Afrodescendentes, entidades do Movimento Negro, sindicatos e universidades que pesquisam e trabalham com a temática afrodescendente. ${ }^{4}$

Conforme consta na página oficial da Secretaria de Estado da Educação (SED), esse espaço tem como proposta, além de suprir a demanda referente à ERER na educação estadual,

[...] ações concretas de curto e longo prazo, garantir a visibilidade e promover o desenvolvimento e a participação da população afrodescendente do Estado de Santa Catarina no âmbito educacional a partir do que dispõe a Lei Federal 10639/03, que altera a Lei no 9.394/96, tornando obrigatório incluir no currículo oficial da rede de ensino a temática "História e Cultura Afro-Brasileira", bem como do que dispõe a Lei Complementar 263/04.

O NEAD foi responsável por importantes eventos da educação estadual relacionados à temática, além de organizar a formação de professores e gestores da rede, propor agendas importantes ao governo estadual e orientar os encaminhamentos relacionados à temática. A partir da criação do NEAD, foram criadas nas 26 gerências subgrupos de discussões da ERER. A intenção era de que, em cada região, houvesse grupos de estudos 
imbuídos de pensar a implementação da Lei nas escolas correspondentes. O núcleo e suas subdivisões funcionaram conforme proposto durante alguns anos. Devido à burocracia e à integração de outras temáticas de diversidade, contribuíram para o enfraquecimento das ações. "Apesar de não existir nenhum documento oficial, fazendo cessar os efeitos da Portaria que instituiu o núcleo, desde 2008 este deixou de existir" (MOREIRA, 2014, p. 30).

No material intitulado Orientações para a Educação Básica e Profissional da Rede Pública Estadual do ano de 2005, há um item dedicado à educação afrodescendente, especificamente. Ali, é acentuada a existência do NEAD, seus objetivos, ações realizadas até o momento e o planejamento para anos posteriores, que englobava

[...] a elaboração do Estatuto do NEAD; a formulação dos pressupostos teóricos, didático-pedagógicos, políticos, filosóficos e administrativos para a implementação das Leis 10.639/03 e LC 263/04; a formulação e execução de propostas e encaminhamentos para o atendimento das demandas educacionais da população negra de Santa Catarina; o mapeamento das necessidades das comunidades remanescentes de quilombo com o objetivo de implementação da LC 263/04 de âmbito estadual; o mapeamento das experiências educativas com ênfase para o combate ao racismo, valorização do negro e o estímulo ao ingresso e permanência de educandos nas escolas estaduais e no ensino superior; a realização de diagnóstico sobre a trajetória educacional de negros e negras; a consultoria do MEC; o assessoramento para as GEECTs [Gerências de Educação, Ciência e Tecnologia] e acompanhamento das ações; a organização do Fórum Permanente; a realização de Seminário para socialização dos projetos bem sucedidos nas gerências de ensino (SANTA CATARINA, 2005, p. 25).

O exame dos documentos mostra que não há indicação sobre como e quando devem ser incluídas as Orientações e Diretrizes referentes a ERER, ainda que a todo momento haja menção ao respeito à diversidade dos educandos. Entretanto, essa diversidade, o que ela significa, ao que corresponde, e quais suas implicações não são especificados.

\section{A Lei Federal 10.639/2003 como proposta de alteração das Propostas Curricu- lares do Estado de Santa Catarina}

No ano de 2014 foi lançada a nova Proposta Curricular da Secretaria de Estado da Educação de Santa Catarina, resultado de um trabalho cooperativo de consultores contratados e professores voluntários, que se reuniram regularmente durante um semestre para avaliar os novos parâmetros educacionais catarinenses, contando com a participação de cerca de oito mil professores. Houve ainda a possibilidade de avaliação pública do produto final, o que tornou o processo de elaboração mais democrático. Nesse documento, a adequação ao proposto pela 10.639/03 surge sistematizada e de forma esmiuçada.

Nos chama a atenção a nova abordagem ao conceito de diversidade, numa perspectiva muito diferente da proposta anterior. A discussão já principia citando a 
hierarquização das diferenças, inclusive a racial. A diversidade, sob o novo olhar, não se reduz

[...] aos grupos considerados excluídos, caracterizados como "os diferentes", "os diversos", ou seja, como aqueles que não atendem à norma ou ao padrão estabelecido a partir de uma identidade hegemônica como referência. A diferença está em todos nós! Somos pessoas únicas e em constante transformação num ambiente, também, em constantes transformações (SANTA CATARINA, 2014, p. 54).

Nesse ínterim, desenrola-se uma construção sobre o que é então esse princípio e como está atrelado ao cotidiano escolar. Assim, a

[...] diversidade, entendida como enriquecimento, possibilidade, processo de construção, é própria dos seres humanos. É o tema que se impõe para que possamos construir uma escola pautada no direito à educação e no direito à diferença e na formação integral do sujeito como movimentos que impulsionam a superação de perspectivas monoculturais, etnocêntricas e hegemônicas que determinam os modos de fazer educação escolar (SANTA CATARINA, 2014, p. 56).

Nesta perspectiva, observamos um avanço nas discussões sobre diferença, e em como os espaços educativos devem portar-se a respeito, qual a postura a ser adotada. Ainda que apareça novamente como parte da educação inclusiva, já é aberto o diálogo sobre o que fazer para lidar com a diversidade, ao passo que se reconhece a existência de sujeitos com trajetórias variadas, e que todas devem ser legitimadas (GOMES, 2007, p. 102). Outro dado importante é que discutir a diversidade deixa de ser "tarefa" de professores/as negros/as, que "tinham" a incumbência solitária e quase obrigatória de falar sobre a diversidade, especialmente a étnico-racial.

O documento aponta questionamentos, tais como quem são os sujeitos da diversidade, a quem referenciam. De maneira romantizada, afirma-se que "os sujeitos da diversidade somos todos nós" e, após, enfatiza que, destacadamente, "os grupos que vivenciaram processos de preconceito e discriminação, principalmente, no percurso formativo" (SANTA CATARINA, 2014, p. 57).

Considerando especificamente a ERER, a Proposta situa o educador e o gestor sobre qual é a abordagem da temática, citando que ela

[...] se aloja na ideia da desconstrução dos modelos e instituições escolares assumidos como únicos e propõe a construção de possibilidades educativas que levem em conta a pluralidade étnica. Esse processo de desconstrução e construção, levando em conta a identidade cultural brasileira e as suas pertenças, pode se constituir em prática constante de reflexão, no interior da escola (SANTA CATARINA, 2014, p. 66).

Ainda, aproximando-se do cerne da ERER, diz que esta

[...] contesta a ausência dos sujeitos étnicos de matriz africana e indígena no "território do conhecimento". E, em sendo o currículo um espaço de tensões e disputa, traz em seu histórico registros de exercícios de diálogo, por diversos segmentos da 
sociedade brasileira, em defesa de uma escola manifestadamente plural. Nesse percurso, a abertura proposta pela ERER para os currículos encaminha novos saberes, novas formas de ensinar e novos comportamentos para aqueles a quem se dará essa oportunidade de aprender. São novas perguntas que nos trarão estudantes para as quais serão necessárias novas respostas. É significativo refletir sobre o quão importante é a articulação dos saberes da escola com os saberes trazidos pelos sujeitos da escola. É ético que a escola garanta que essa mescla produza outros saberes, outras racionalidades, outras interatividades e posturas no âmbito das relações étnico-raciais. Enquanto isso, novas tensões, exercícios de diálogo vão se estabelecendo no âmbito do currículo e as representações dos grupos apresentados de forma subalterna, questionadas por três princípios da educação das Relações Étnico-Raciais: a) a busca de uma consciência política e histórica da diversidade (...) b) o fortalecimento de identidades e de direitos (...) c) ações educativas de combate ao racismo e às discriminações (SANTA CATARINA, 2014, p. 67-68).

Embora a temática referente aos afro-brasileiros apareça atrelada à temática indígena, de uma forma que se excluem as especificidades relativas a grupos com vivências, culturas e trajetórias tão distintas (uma premissa errônea que deve até mesmo nos barrar de agrupar os indígenas como sendo um grupo único e coeso, uma vez que há mais de trezentas etnias no território nacional, cada qual com sua própria cosmovisão, história e idioma), ${ }^{5}$ há uma nítida preocupação em elucidar questões importantes que envolvem a ERER.

Em relação ao pertencimento, que busca oferecer uma mudança no não-lugar do negro na escola (ROMÃO, 2005, p.17), há o lembrete de que

[...] precisamos afirmar lugares positivos para as temáticas que nos trazem a ERER em nossa prática e reflexão pedagógicas. Precisamos refletir sobre o que ensinamos e sabemos sobre nossa matriz de base histórico-cultura africana. A ERER propõe a reeducação dos sujeitos sociais e da escola. Reeducar tendo como referência os estudos das populações africanas e indígenas, seu legado, suas influências e suas contribuições às formas de ser da população brasileira e catarinense. Indica (re) conhecer que a perspectiva eurocêntrica da escola não favorece a presença e a contribuição de outros sujeitos étnicos na intencionalidade do fazer pedagógico. Que sendo pública, a escola é de todos e para todos e o eurocentrismo é um obstáculo para a igualdade (SANTA CATARINA, 2014, p. 68).

É um repensar de toda a prática docente, desde a eleição dos tópicos a serem tratados, até a abordagem usada no processo. Nesta reorganização, orienta-se praticar a aproximação de todos os sujeitos para a os vínculos estabelecidos durante a construção do conhecimento e da identidade. Ao passo que o educando negro enxerga sua história com olhos valorosos, se conecta e firma seu pertencimento a esse espaço tão caro à população afro-brasileira.

Partindo para a parte mais específica, em que se recomenda possibilidades de trabalho por área, ressaltamos o enfoque dado à Lei 10.639 e à Lei 11.645, promulgada em 2008 , reafirmando que 
[...] é obrigatório o estudo da História e Cultura Afro-brasileira e Indígena (BRASIL, 2003b, 2008b) em seus diversos aspectos históricos e culturais que caracterizam a formação da população brasileira. Isso inclui o estudo da história da África e dos africanos, a luta dos negros e dos povos indígenas no Brasil, a cultura negra e indígena brasileira e o negro e o índio na formação da sociedade nacional, resgatando as suas contribuições nas áreas social, econômica e política, pertinentes à história do Brasil (SANTA CATARINA, 2014, p. 140-141).

Relativo à área de Geografia, há um olhar muito sensível sobre o direcionamento do trabalho do educador, quando chama a atenção para a

[...] natureza, apropriada pelos seres humanos e transformada por suas dinâmicas naturais e por meio do trabalho, produz paisagem, um espaço indissociável natureza - sociedade, que expressa as manifestações políticas, econômicas, culturais e socioambientais em um espaço-tempo. O espaço vivido é o lugar, onde os seres humanos se reconhecem, constituem identidades, atuam como cidadãos e a partir do cotidiano fazem a leitura do mundo. As relações de poder neste espaço, suas ocupações e delimitações no cotidiano ou nas relações entre Estados Nacionais, entre diferentes instituições e representações da sociedade nas mais diversas escalas geográficas local, regional, nacional e global em que a vida acontece, transforma este espaço em território (SANTA CATARINA, 2014, p. 143).

Sob esta perspectiva, naturalmente visualizamos a possibilidade de agregar a temática africana e afro-brasileira, pensando, por exemplo, numa atividade que envolva o estudo do cotidiano em territórios de resistência de escravos (SILVA, 1984) ou também no trânsito de africanos e africanas livres em províncias do território nacional. É apenas um dos muitos temas que podem emergir, com tratamento oposto ao que é comumente sugerido pelos livros didáticos e materiais que não se adequaram à Lei (e que insistem em manter a imagem das populações de origem africana como conformadas diante das atrocidades da escravidão, ou sem uma visão para além dessa).

Outra sugestão significativa da Proposta foca no

[...] desenvolvimento de um trabalho de pesquisa, problematizado a partir da experiência cotidiana do sujeito inserido em seu contexto histórico, utilizando-se das metodologias da História Oral, por exemplo, aproxima de forma significativa o sujeito da aprendizagem e seu objeto de pesquisa - a vida humana e suas relações. Assim, evidentemente, as narrativas não serão tratadas como verdade absoluta, mas o discurso será contextualizado e ressignificado à luz da historiografia pertinente ao tema proposto (SANTA CATARINA, 2014, p. 146).

Além de configurar uma proposição mais democrática de (re)escrever os percursos historiográficos dos sujeitos, essa metodologia confere legitimidade a uma gama de aspectos da temática que defendemos aqui, favorecendo uma reorganização e sistematização do conhecimento, onde memória cultural, força e resistência tornam-se protagonistas (GOMES; SILVA, 2002, p. 66). 


\section{Considerações finais}

Podemos considerar a Lei de Diretrizes e Bases da Educação Nacional como o mais importante marco legal educacional de nosso país. Inúmeros agrupamentos da sociedade civil assistiram, através dela, a institucionalização de suas reivindicações. Ainda assim, muitas mudanças ocorreram após sua promulgação, conferindo um refinamento contínuo, como é comum a todos os processos democráticos. A alteração mais expressiva na educação igualitária e que tenha como objetivo pensar as relações raciais - tema estruturante de nossa sociedade - foi a Lei Federal 10.639/2003.

Ao refletirmos como ocorre a adequação a essas alterações a partir das discussões curriculares, concluímos que os processos acontecem, mesmo que de maneira ainda tímidos. Ao investigar a Proposta Curricular de Santa Catarina de 2014, vimos como há um maior desdobramento (inclusive teórico-metodológico) sobre o que é diversidade, como contemplá-la e o papel do educador nesse processo - algo que não estava aparente na Proposta Curricular do ano de 1998. Um ponto para abertura de mais debates reside na colocação de toda e qualquer diversidade dentro da mesma "caixa", como se a população negra e indígena fossem diversos, porém homogêneos. Contradições que precisamos continuamente discutir a medida que readequamos tanto os marcos legais como as propostas mais locais, dos estados e municípios.

Recebido em 11/09/2016 e aprovado em 11/11/2016

\section{Notas}

1 Para maiores informações <http://www.planalto.gov.br/ccivil_03/Constituicao/Constituicao.htm>.

2 Para maiores informações, verificar RIBEIRO e CUSTÓDIO (2008), LUCINDO (2013) e BOFF (2015).

3 Acessei este material através da biblioteca de uma escola de educação básica municipal de Florianópolis, no ano de 2013.

4 Maiores informações presentes em <http://www.sed.sc.gov.br/educadores/nead> Acesso em 15/11/2015.

5 Ver <http://www.brasil.gov.br/governo/2012/08/brasil-tem-quase-900-mil-indios-de-305-etnias-e-274-idiomas> Acesso em 15/11/2015. 


\section{Referências}

BARROS, Surya A. P (org.). Estado da Arte da Produção sobre História da Educação da População Negra no Brasil. Vitória ( ES) : SBHE/Virtual Livros, 2015.

BOFF, Virginia Ferreira. Educação no pós-abolição: a escolarização de afrodescendentes em Florianópolis-SC (1888-1930). 2015. Dissertação (Mestrado em Educação). Programa de Pós-graduação em Educação da Pontifícia Universidade Católica do Rio Grande do Sul

BRASIL. Constituição da República Federativa do Brasil. Brasília, DF, Senado, 1998. Ministério da Educação /Secretaria da Educação Continuada, Alfabetização e Diversidade; Orientações e Ações para a Educação das Relações Étnico - Raciais. Brasília: SECAD, 2006.

Diretrizes Curriculares Nacionais: Educação Básica. Brasília: MEC, 2006 Parecer CNE/CP 003/2004 . Diretrizes Curriculares Nacionais para a Educação das Relações Étnico-Raciais e para o Ensino de História e Cultura Afro-Brasileira e Africana. Brasília: MEC, 2004. Presidência da República. Casa Civil. Subchefia para Assuntos Jurídicos. Lei n. 10.639, de 9 de janeiro de 2003. Brasília: SAJ, 2003.

CARDOSO, Paulino de Jesus Francisco et al. Multiculturalismo e educação: experiências de implementação da lei federal 10.639/03 em Santa Catarina. Itajaí: Casa Aberta, 2008.

CARDOSO, Paulino de Jesus Francisco. A vida na escola e a escola da vida: experiências educativas de afrodescendentes em Santa Catarina no século XX. ROMÃO, Jeruse. História da educação do Negro e outras histórias. Brasília: SECAD, 2005.

GOMES, Nilma Lino et al. Experiências étnico-culturais para a formação do professores. Autêntica, 2002.

LIMA, Ivan Costa; ROMÃO, Jeruse; SILVEIRA, Sônia Maria. Os negros e a Escola Brasileira. Núcleo de Estudos Negros, 1999.

LUCINDO, Willian R. S. Os desafios do Pós-Abolição: a luta pela emancipação. Tempos Acadêmicos, n. 8, p. 1-19, 2013.

MOREIRA, Maria Aparecida Rita. A educação para as relações étnico-raciais e o ensino de literatura no ensino médio: diálogos e silêncios. Tese (Doutorado em Literatura). Programa de Pós-graduação em Literatura da Universidade Federal de Santa Catarina, 2014.

RIBEIRO, N. G; CUSTÓDIO, L.V. Estudo sobre a escolarização do negro em Santa Catarina: municípios de Itajaí, Lages, Criciúma, e Florianópolis. Itajaí: UDESC; Casa Aberta, 2008.

ROMÃO, Jeruse (Org.). História da educação do negro e outras histórias. Ministério da Educação, Secretaria de Educação Continuada, Alfabetização e Diversidade, 2005.

Experiências educacionais em Santa Catarina. Cadernos de Pesquisa, Fundação Carlos Chagas, n. 63, p.140, 2013. 
SANTA CATARINA. Secretaria de Estado da Educação e do Desporto. Proposta Curricular de Santa Catarina, 1998.

Secretaria de Estado da Educação e do Desporto. Proposta Curricular de Santa Catarina, 2014. Secretaria de Estado da Educação, Ciência e Tecnologia. Orientações para a Educação Básica e Profissional da Rede Pública Estadual. 2005.

SILVA, Petronilha Beatriz Gonçalves; BARBOSA, Lúcia Maria de Assunção. O pensamento negro em educação no Brasil. São Carlos : Editora da UFSCAR, 1997.

Aprendizagem e ensino das africanidades brasileiras. Superando o racismo na escola.

Brasília: MEC/Secad, p. 155-172, 2005.

Prática do racismo e formação de professores. Múltiplos olhares sobre a educação e cultura. Belo Horizonte, UFMG, p. 168-178, 1996. 